\title{
A Invenção do Sujeito
}

\author{
Gillianno José Mazzetto de Castro \\ Universidade Católica Dom Bosco, MS, Brasil.
}

\author{
Marcio Luis Costa \\ Universidade Católica Dom Bosco, MS, Brasil.
}

\begin{abstract}
Resumo: O presente artigo tem por objetivo fazer uma reflexão sobre o modelo de sujeito Ocidental que foi construído a partir da modernidade e discutir como se dá a interação, ou a ausência dela, entre o paradigma do sujeito lógico e do sujeito ontológico na pesquisa em Psicologia da Saúde. Tal caminho será feito por meio de algumas correntes de pensamento que influenciaram a forma como o indivíduo moderno concebera o mundo, são elas: o racionalismo cartesiano, os movimentos do século XVI como uma decisão pela categoria de sujeito, o criticismo kantiano e a invenção do conceito de "homem", por meio da antropologia, e, por fim, o giro feito pela Fenomenologia husserliana tanto na síntese ativa, como na síntese passiva, que acabaram por propor o corpo próprio como um conceito que permite pensar a relação entre o sujeito e o mundo. Este artigo utiliza-se do método fenomenológico e da pesquisa bibliográfica como metodologia de trabalho.
\end{abstract}

Palavras-chave: Sujeito, Fenomenologia, Psicologia.

\section{The Invention of the Subject}

Abstract: This article aims to reflect on the modernity-built western model of subject and discuss how the interaction, or lack thereof, occurs between the logical and the ontological subject paradigm in Health Psychology research. This will be done through some thought currents that influenced how modern individuals conceive the world, namely: the Cartesian rationalism, the sixteenth century movements as a decision for the category of subject, the Kantian criticism and the invention of the concept of "man" by anthropology. Finally, we will address Husserl's phenomenology approach to active synthesis as well to passive synthesis, which ultimately proposes one's own body as a concept that allows us to consider the relationship between the subject and the world. This article makes use of the phenomenological method and literature as its working methodology.

Keywords: Subject, Phenomenology, Psychology.

\section{La Invención del Sujeto}

Resumen: El presente artículo tiene por objetivo hacer una reflexión sobre el modelo de sujeto occidental que fue construido a partir de la modernidad y discutir cómo se da la interacción o la ausencia de ella entre el paradigma del sujeto lógico y del sujeto ontológico en la investigación en Psicología de la Psicología de la Salud. Este camino se hará por medio de algunas corrientes de pensamiento que influenciaron la forma en que el individuo moderno concibió el mundo, son ellas: el racionalismo cartesiano, los movimientos del siglo XVI como una decisión por la categoría de sujeto, el criticismo kantiano y la invención del concepto de "hombre", por medio de la antropología, y, por fin, el giro hecho por la Fenomenología Husserliana tanto en la síntesis activa, como en la síntesis pasiva, que acabaron por proponer el cuerpo propio como un concepto que permite pensar la relación entre el sujeto y el mundo. Este artículo se utiliza del método fenomenológico y de la investigación bibliográfica como metodología de trabajo.

Palabras clave: Sujeto, Fenomenología, Psicología. 
O presente artigo pretende pensar sobre o sujeito na modernidade. A questão do sujeito ocupa uma posição importante dentro das reflexões em Psicologia com as suas várias abordagens (Figueiredo, 2016; Figueiredo; Santi, 2016). Se a Psicologia se apresenta como um campo plural, o debate sobre o sujeito também acaba sendo marcado por essa pluralidade. Autores como González-Rey (2003), comentando sobre o debate do sujeito em Psicologia, afirmam: "a subjetividade é um complexo e plurideterminado sistema" (p. IX). A pretensão desse artigo é a de, por meio do instrumental fenomenológico, contribuir com a Psicologia da Saúde no que toca ao papel do sujeito das pesquisas dentro dessa área. Para tanto se pensará o sujeito a partir da discussão sobre as condições originárias, ou genéticas (Husserl, 1998) que nasce dentro da Fenomenologia sob a forma de pergunta pelas realidades que dão possibilidade ao fato de ser existente no mundo como pessoa. Por condições originárias ou genéticas se compreende as estruturas que permitem e são causa de determinada dimensão do real.É o solo a partir do qual se assentam as construções teóricas.

De maneira particular, objetiva-se pensar como foi se estabelecendo a relação entre o sujeito lógico, como categoria de um ente que é capaz de construir uma relação com a realidade a ponto de considerá-la objeto e o sujeito ontológico, que é cada pessoa na singularidade da sua vida. A pergunta pelo sujeito lógico e pelo sujeito ontológico e os seus efeitos nas pesquisas, de maneira particular as pesquisas em Psicologia da Saúde, tem por intento auxiliar o leitor na reflexão sobre o próprio fazer científico, não apenas como um ato teórico ou abstrato, mas sim como o exercício de se construir como ser humano, na sua singularidade de existente que interage e busca entender o mundo.

Quando falamos em sujeito nas pesquisas em Psicologia da Saúde, de qual tipo de sujeito estamos falando? Quais são as características intrínsecas a esse ente quando o nominamos sujeito da pesquisa? São características predicativas e, portanto, de caráter denominativo, isto é, "o que" é determinada realidade ou de caráter inerente, ou seja, "que" é determinada realidade? Há uma passagem natural entre o sujeito lógico das nossas pesquisas ao sujeito ontológico da vida dos pesquisadores? Essas são perguntas que permitem pensar uma invectio subjecti, ou seja, a forma como o sujeito foi sendo construído dentro do pensamento Ocidental, principalmente a partir da modernidade, e a maneira com a qual elementos dessa construção estão presentes na pesquisa em Psicologia da Saúde.

Ao se pensar dentro dessa área do saber psicológico, de forma particular a luz daquilo que vem sendo discutido como saúde dentro do campo da saúde coletiva, é possível observar que a relação entre sujeito, bem-estar, adoecimento e práticas de Saúde (Taylor, 2002) parece supor um sujeito não apenas como uma entidade abstrata ou racional mas como um ser com várias dimensões e que está em relação com a sociedade, daí também a preocupação dessa área da Psicologia em discutir temas como a Saúde coletiva (Matarazzo, 1982) ou ainda Saúde como um fenômeno Biopsicossocial (Dimenstein, 1998; Silva, 1992; Spink, 2003). O fato de algumas abordagens da Psicologia da Saúde proporem a Saúde como uma realidade Biopsicossocial acaba contribuindo para a reflexão sobre o sujeito que pratica pesquisa, pois, só se é possível pensar a Saúde como um fenômeno complexo se há uma realidade complexa, com uma constituição genética, que permite pensá-la. Contudo, pode-se perguntar: o modelo de sujeito suposto na forma de constituição do saber Ocidental coaduna com a vida das subjetividades que se constroem como pesquisadores que possuem uma dimensão Biopsicossocial? Há, no modelo do sujeito lógico, espaço para a complexidade de subjetividades ontológicas Biopsicossocialmente constituídas?

A suspeita desse estudo é a de que a passagem do conceito lógico de sujeito à vida do pesquisador não é linear nem homogênea. O sujeito lógico da pesquisa, por se tratar de uma estrutura lógico-formal sem conteúdo prévio, considerando que ele é classificado pelo fato de ser sujeito parece ser inversamente proporcional ao sujeito ontológico, o existente, que exerce os seus modos de ser no movimento de dar razões às suas possibilidades existenciais e apresenta-se como finito e mortal, corpóreo e vulnerável.

Os efeitos da pergunta pelo sujeito lógico e sujeito ontológico nas pesquisas, de maneira particular às pesquisas em Psicologia da Saúde, podem ser vistos quando, por exemplo, se pergunta pela qualidade de vida do pesquisador no exercício da sua profissão. Ou ainda quando se interroga pelos efeitos das pesquisas em Psicologia da Saúde na vida dos pesquisadores que a fizeram. O sujeito lógico, de matriz cartesiana, não é afetado pelas suas pesquisas, não adoece por causa delas, já as subjetividades ontológicas dos pesquisadores encontram no movimento de estruturar e 
fazer pesquisa um caminho para se construírem como pessoas, dentro de um tempo e espaço.

O projeto da Fenomenologia de Husserl (2012), principalmente aquele presente em textos como $A$ crise das ciências europeias e a fenomenologia transcendental, ancora-se no objetivo de descobrir, na singularidade de cada vida, uma saída para se pensar a realidade a partir do fato de que o ser humano, que busca dar resposta a sua existência, inclusive sob a forma de pesquisa, não é um ente abstrato ou irreal. Husserl (1998) percebeu que a ligação direta entre os atributos lógicos e a constituição ontológica do sujeito acabou produzindo como resultado, o idealismo e o esquecimento da vida concreta das pessoas. Por isso, faz-se necessário redescobrir o sujeito ontológico como pessoa vivente, como ser corpóreo que, por possuir essa constituição, é capaz de aproximar-se da verdade. É o sujeito ontológico das existências possíveis o que sofre as consequências das elucidações do sujeito lógico. É na vida concreta de cada pesquisador que os efeitos da transposição direta entre lógico e ontológico aparecem, ressoam e impactam.

Contudo, para entender melhor a relação entre atributo lógico e constituição ontológica do sujeito é mister voltar às bases da modernidade, mais precisamente ao século XVI, para verificar e entender como o conceito de sujeito foi sendo modificado ao longo da modernidade de maneira gradual e sistemática, produzindo, como efeito, essa imagem de mundo na qual a sociedade hodierna está inserida e da qual é herdeira. Como isso teve início? Quando o sujeito começou a voltar-se sobre si de maneira objetiva e gradual? Quais foram os efeitos da transposição direta entre lógico e ontológico? São essas algumas questões com as quais se buscará dialogar neste artigo.

Para se responder as perguntas acima será feito um caminho a partir de alguns marcos teóricos, a saber: o racionalismo cartesiano e o movimento do século XVI como uma decisão pela categoria de ego. O criticismo kantiano e a invenção do conceito de homem, por meio do estabelecimento de uma antropologia e, por fim, o giro feito pela Fenomenologia husserliana com as sinteses ativas e após, as sinteses passivas.

Antes disso, é mister considerar dois autores, de campos do saber diferentes do fenomenológico, mas que deixaram para esse campo dois alertas importantes com relação ao sujeito. O primeiro é Nietzsche, que, em seu livro Para além do bem e do mal (1886/2009), declara que a modernidade foi constru- ída sobre três superstições que depois foram transformadas em dogmas. Comenta Nietzsche:

[...] E talvez esteja próximo o tempo em que novamente se atentará para o que era necessário para lançar a pedra fundamental das sublimes e incondicionadas construções filosóficas que os dogmáticos até então levantaram, - alguma superstição popular de um tempo imemorial (como a superstição da alma, que, como a superstição do sujeito e do eu ainda hoje não cessou de produzir disparates) (1886/2009, p. 11).

Nietzsche, nessa passagem, denuncia os três movimentos que caracterizam a modernidade, isto é, a eleição do sujeito, a criação do indivíduo moderno como uma antropologia e a hipervalorização do espírito, Geist, em detrimento das demais realidades. $\mathrm{O}$ segundo pensador que alerta sobre a modernidade é Foucault. Em seu livro As palavras e as coisas (2000), o autor diz que "é um reconforto e um profundo apaziguamento pensar que o homem não passa de uma invenção recente, uma figura que não tem dois séculos, uma simples dobra de nosso saber, e que desaparecerá desde que este houver encontrado uma forma nova" (Foucault, 2000, p. 21). Partindo dessas duas considerações: a primeira, de existirem três superstições dogmáticas - o sujeito, o homem e o Espirito. A segunda, de ser o homem, como uma criação recente, é que agora, seguindo o caminho ao qual a pergunta pelo sujeito irá conduzir, se voltará o olhar para os movimentos efervescentes do século XVI que encontraram, na eleição do sujeito, o critério de validação da realidade (Le Breton, 2012).

Entretanto, por que o século XVI foi tão importante para a história do sujeito no Ocidente? Como foi feita a sua invenção? Qual é a sua possível origem? Como se deu a relação do sujeito com o seu corpo? Sobre isso, comenta, Le Breton:

[...] no século XVI, nas camadas eruditas da sociedade, debuta-se o corpo racional, que prefigura nossas representações atuais, aquele que marca a fronteira de um indivíduo em relação ao outro, a clausura do sujeito. É um corpo liso, separado dos outros, em posição de exterioridade com o mundo, fechado em si mesmo (2012, p. 48).

A denúncia de Le Breton é relevante porque foi no século XVI que, no Ocidente, de maneira mais precisa 
na Europa, uma nova mentalidade começou a se afirmar em meio às classes intelectuais e burguesas; surge o modelo do indivíduo burguês expatriado e que precisa de instrumentos cada vez mais precisos e eficazes para objetivar o mundo. São exemplos dessa nova mentalidade quatro obras importantes a saber: De Revolutionibus Orbium Coelestium (1543/1984), de Copérnico, que vai propor um novo modelo de cosmos a partir do paradigma heliocêntrico, e o De corporis Humani Fabrica (1543), de Vesalius, que postulará um novo modelo de relação com o corpo e que, ao mesmo tempo, vai combater o manual do médico romano Galeno, usado por mais de mil anos no Ocidente. "A partir de Vesalius, o homem cosmológico da época anterior não é mais do que caricatura de si mesmo: um cosmos em retalhos se oferece como o mundo por detrás do homem anatomizado, ele se tornou decoração" (Le Breton, 2012, p. 86), os Diálogos (1638) de Galileo, no qual ele propõe o método experimental como novo paradigma para a ciência, por fim, A riqueza das nações (1776) de Smith, que propôs o modelo liberal como a forma de construção da economia moderna.

Dessa forma, podem-se notar quatro movimentos importantes que vão dar um novo horizonte a essa modernidade nascente e da qual a época atual herdará profundas decisões sobre a forma como se pensa a realidade e a verdade. O primeiro é que o burguês, que está sendo forjando na modernidade, se percebe como um cidadão do mundo, uma pessoa cujas fronteiras devem ser transparentes. O segundo movimento nasce dentro do universo religioso, adveniente da Reforma Protestante, com o objetivo de dar ao ser humano a liberdade de se relacionar diretamente com o seu Deus sem a mediação total de uma instituição. $\mathrm{O}$ terceiro movimento se dá em relação à visão de mundo, pois a revolução copernicana e o método experimental de Galileo trouxeram um novo paradigma para o Ocidente. O quarto se dá com Vesalius (1543), quando este propõe pensar o corpo humano como uma máquina e não mais como um microcosmo. Feitas essas considerações passa-se agora a ponderar a partir das estruturas de pensamento que ajudaram a construir a visão do sujeito.

\section{O século XVI e o Cartesianismo: a decisão pelo sujeito}

O século XVI nasce no cenário Ocidental como um período no qual as revoluções culturais, religiosa e políticas, tais como o Renascimento, a reforma pro- testante, as navegações produzem no ser humano uma vontade de emancipação de todas as amarras e mediações. Contudo, em qual fonte Descartes e os pensadores de sua época foram beber para propor o ego, entendido como sujeito lógico, como ícone do período? A construção do sujeito cartesiano está ancorada em dois pressupostos fundamentais e em um postulado. O primeiro é um pressuposto gramatical, o "Eu penso", Ego Cogito, o segundo é uma relação lógica o "Logo, existo", ergo sum, e a constituição do Subjectus (Furlanetto, 1965) como aquele que ocupa uma posição inferior na hierarquia lógica e, por fim, o postulado que sustentará parte da modernidade, a saber: todo real é, a fortiori, verdadeiro. Sobre o ego que valida a si mesmo e ao mundo, comenta Descartes: "quando alguém diz: Penso, logo sou, ou: existo, ele não conclui a sua existência de seu pensamento como pela força de um silogismo, mas como uma coisa conhecida por si; ele a vê por simples inspeção do espírito" (1637/2001, p. 58). Aqui já é possível perceber como essa nova forma de olhar o ser humano está se estruturando, pois, ao afirmar a evidência do Penso, logo sou como existente e apodítico, Descartes acaba por colocar a condição lógico-gramatical como critério de validação da própria realidade, a tal ponto que, para confirmar tal tese, basta apenas "verificar o espírito". Com isso, vê-se uma nova abordagem do fenômeno humano diferente daquela que a Antiguidade e a Idade Média haviam elaborado no Ocidente, pois, com o cartesianismo, o critério de validação da realidade e do sujeito não é mais o cosmos ou a vida social, mas o próprio sujeito que se mostra de maneira evidente a partir de si mesmo (Descartes, 1637/2001). Surge o ego como categoria ativa, o primeiro passo para o sujeito lógico contemporâneo

Descartes apropria-se de um ente gramatical "Eu", faz com ele uma inferência lógica "Penso, logo" e dá um salto afirmando que aquilo que é gramatical e logicamente possível deve ser a realidade, ou seja, ele acaba por transformar um enunciado de linguagem e de teoria do conhecimento em uma realidade ontológica, "logo, sou” (Descartes, 1637/2001; 1641/2004).

Ao se pensar tal realidade dentro do horizonte da pesquisa em Psicologia da Saúde é possível notar alguns traços herdeiros do modelo de pensamento moderno. Por exemplo, a validade dos enunciados científicos e comparação ao seu estatuto de realidade. Um conceito ou dado científico, em muitos discursos e enunciados de pesquisa, ganha um estatuto ontológico, mesmo sendo enunciados lógicos. 
Quem garante que um paradigma ou axioma científico de fato tem correspondência na realidade? Qual a real incidência de conceitos que são considerados plausíveis ou lógicos por determinado campo do saber? Tal consideração chama a atenção para o impacto real das pesquisas em Psicologia da Saúde na vida do pesquisador e dos participantes. As discussões sobre as abordagens, modelos teóricos, teorias sobre o sujeito, conceito de Saúde, conceito de qualidade de vida, muito mais do que realidades teóricas, devem ser consideradas a partir da capacidade de construir ou destruir realidades ontológicas concretas. Por exemplo, a reflexão sobre o conceito de Saúde como tratamento de doença, e a concepção de Saúde como um fenômeno Biopsicossocial e o impacto concreto que essas duas visões causaram na vida das pessoas.

Outro passo importante na história do conceito de sujeito no Ocidente foi a objetivação do próprio sujeito. Um dos autores que contribuíram para esse processo foi Kant. Com ele o indivíduo passa a ser o objeto de estudo do próprio sujeito.

\section{Immanuel Kant e a invenção do homem moderno}

Se com Descartes e com os movimentos do século XVI o sujeito moderno ganha força, sob a forma de um arranjo lógico-gramatical com consequências existenciais; com Kant pode-se observar a tentativa de constituição de um sujeito desenhado por meio de um estatuto lógico-transcendental. A proposta kantiana coloca o ser humano como o espaço mesmo do universal. Com ele o sujeito é retirado do seu quartel cartesiano que se autojustifica, o conceito de ego e é apresentado como um Weltürber, isto é, um cidadão do mundo. Para se entender melhor como isso é feito, partir-se-á de três textos do autor de: Crítica da Razão Pura (1781/2001); Fundamentação da Metafísica dos Costumes (1785/1974); e um texto menor, de 1798, mas amplamente ligado ao projeto do primeiro, que se intitula Antropologia do ponto de vista pragmático (1798/2006).

Kant em sua Crítica da Razão Pura estabeleceu uma dicotomia que norteia toda a sua obra, inclusive aquelas de finalidade prática, a relação entre noumeno e o fenômeno, que compreenderia os conteúdos do real (noumeno) e as imagens desses conteúdos a que o sujeito tem acesso (fenômeno). Em suas reflexões, ele propõe um diálogo entre essas duas instâncias para dar um estatuto de validade universal ao conhe- cimento e àquele que conhece. Esse é, de certa forma, o mesmo objetivo de sua antropologia, pois nela Kant, partindo da experiência do indivíduo no mundo busca dar à vida humana uma validade e uma abrangência de caráter universal. Com isso, ele almeja que o sujeito adquira uma dignidade não somente validada por si mesmo, como no caso do "eu" cartesiano, mas em todos os lugares, isso será feito por meio da vida moral. "[...] a moralidade é a única condição que pode fazer de um ser racional um fim em si mesmo. [...] a humanidade enquanto capaz de moralidade é a única coisa que tem dignidade" (Kant, 1781/2003, p. 234). Eis como Kant apresenta a sua antropologia:

Uma doutrina do conhecimento do ser humano sistematicamente composto (antropologia) pode ser tal do ponto de vista fisiológico ou pragmático. - O conhecimento fisiológico do ser humano trata de investigar o que a natureza faz do homem; o pragmático o que ele faz de si mesmo, ou pode e deve fazer como ser que age livremente (1798/2006, p. 21).

Como se pode ver na citação acima, Kant expõe o seu projeto para essa nova ciência que junto com as demais ciências humanas vai transformar, mais uma vez, a constituição do sujeito no mundo. A partir daí o ser humano deixa de ser apenas o sujeito que objetiva o mundo e passa a ser, em sentido estrito, objeto da sua própria ciência e da sua própria reflexão. A antropologia kantiana apresenta-se como uma doutrina cuja finalidade é levar o indivíduo à liberdade, projeto esse já enunciado em sua obra $A$ Metafísica dos costumes contendo a Doutrina do Direito e a Doutrina da Virtude (1797/2003). Nessa, ele introduz, no cenário da reflexão Ocidental sobre o ser humano, um tema importante, a sua estrutura fisiológica como fator determinante para o seu projeto de construção como cidadão do mundo. Em várias passagens da sua Antropologia, ele parte do corpo para traçar um caminho universalmente válido de liberdade para o indivíduo. Por exemplo, para falar sobre o temperamento, Kant afirma:

Do ponto de vista fisiológico, quando se fala do temperamento entende-se a constituição corporal (a estrutura forte ou fraca) e a compleição (os fluídos, aquilo que no corpo se move regulado pela força vital, onde também se incluem o calor e o frio na elaboração desses humores) (1798/2006, p. 21). 
Aqui é possível ver um tema relevante. Ao se considerar a constituição corporal da pessoa como um dado importante. Kant, no movimento de fundação de uma nova forma de ciência, acaba por transformar o estatuto do então sujeito cartesiano. Com a sua contribuição o sujeito, agora pensado como, transcendental, que percebe a si mesmo e ao mundo, se insere dentro de um novo status quo de objeto de estudo de um determinado tipo de ciência. A Antropologia se ocupará desse novo fenômeno, isto é, do indivíduo pensado sob a categoria de homem como um sistema.

Falando da capacidade de representação, algo de fundamental importância para a constituição de um sujeito que valida a realidade, Kant afirma sobre a dimensão sinestésica: "[os sentidos] é aquele em que o corpo humano é afetado pelas coisas corporais” (Kant, 1798/2006, p. 52). Diante disso, segundo Foucault (2000), percebe-se que com Kant o corpo começa a ganhar um espaço dentro do cenário da reflexão sobre a pessoa humana, porém não como estrutura identitária vital, mas como organismo. Ele é pensado dentro de uma anatofisiologia, como körper, estrutura organizada, máquina anatômica que não constitui uma identidade, mas está a serviço dela (Le Breton, 2012). Aqui se faz necessária uma digressão no que diz respeito à especificidade da palavra Körper em relação a outra palavra alemã para corpo, que é Leib. Em alemão, Körper é o organismo, a somatória dos órgãos, a estrutura. Já Leib é o ser vivo, o corpo vivente. Essa pequena sutileza linguística vai fazer toda a diferença em autores, como é o caso de Kant, que pensam a partir dessa estrutura linguística.

Tal concepção mecanicista do corpo e da vida marcará profundamente não apenas o pensamento kantiano, mas também a abordagem do paradigma de ciência moderna quando se trata do ser humano. Pensando como esse modelo apresenta-se dentro das reflexões da Psicologia da Saúde é possível perceber que abordagens como a da biomédica tomam por base o modelo de individualidade como um organismo que funciona por meio de processos químicos-mecânicos, anatofisiológicos (Demarco, 2003). À dimensão social, cultural são reservados papéis secundários dentro desse modelo. Após considerar esses pontos é possível se perguntar: qual é a contribuição da Fenomenologia para a reflexão sobre o Sujeito? Como essa reflexão pode ajudar a compreender os sujeitos das pesquisas em Psicologia da Saúde?

\section{O primeiro sujeito em Husserl: as sínteses ativas}

A Fenomenologia como escola de pensamento surge a partir das reflexões de Husserl no início do século XX, inspirando-se na palavra fenômeno, aquilo que aparece. Ele elabora um sistema de pensamento cujo objetivo é conhecer as realidades tal como elas aparecem à consciência (Husserl, 1950). Ele atribui a evidência fundadora do cartesianismo: “[...] o ego cogito, como domínio último e apoditicamente certo sobre o qual deve ser fundamentada toda a filosofia radical" (Husserl, 2001, p. 36). Portanto, é no fato da consciência ser transparente para si mesma que se estruturam as bases para uma primeira reflexão sobre a relação entre consciência e fenômeno, sujeito e realidade.

Entretanto, com Husserl, o critério de validação do conhecimento não está mais apenas no "Eu" cartesiano, ou nas categorias do a priori do sujeito transcendental kantiano, mas passa a ser a relação entre o sujeito que conhece e a realidade que se dá a conhecer. A isso ele vai dar o nome de intencionalidade, dizendo que toda consciência só é consciência de alguma coisa e todo objeto só se torna objeto porque se dá a uma consciência que o conhece (Husserl, 2001). Após afirmar isso, Husserl começa a traçar um caminho para a sua nova ciência filosófica, a Fenomenologia, por meio do que ele mesmo vai chamar de método fenomenológico. Tal método parte das relações entre a consciência do sujeito e os objetos, (faenómena), fenômenos, que se dão a ela, através de uma interação entre o objeto que se apresenta noema, e o ato de perceber, noésis. É por meio desse binômio que se dá o fenômeno da experiência. Porém, as experiências da consciência no mundo construídas como vivências, Erlebnis, ainda possuem muitas imprecisões que não colaboram com o processo de compreensão do fenômeno como ele se apresenta na sua intencionalidade ao sujeito. $\mathrm{Na}$ linguagem de Husserl, pode-se afirmar que a relação noético-noemática, isto é, entre o objeto que se dá a um sujeito e de um indivíduo que está voltado intencionalmente para um objeto, construída por meio das vivências ainda mantém a experiência da realidade apenas como algo interno ao sujeito

Para evitar que a Fenomenologia caísse no subjetivismo no qual a experiência do mundo estaria restrita apenas as impressões percebidos pelo sujeito, Husserl propõe a atitude fenomenológica com o obje- 
tivo de "elevar a uma reflexão em âmbito da consciência científica as características próprias da atitude natural" (Husserl, 1950, p. 4), isto é, fazer com que as experiências oriundas das vivências sejam submetidas ao rigor da reflexão criteriosa para que, assim, livre de todos os pré-juízos e pré-conceitos, se possa realmente acessar o fenômeno como ele se dá à consciência, de maneira pura. Este propósito objetiva dar um estatuto de validade e solidez às pesquisas e ao método fenomenológico, fazendo assim com que as experiências impuras das vivências adquiram um valor universal.

Contudo isso só pode ser feito mediante aquilo que o Husserl vai chamar de epoché, que nada mais é do que o "colocar entre parênteses" a realidade para que, livres de influências e preconceitos, possa-se chegar ao fenômeno tal como ele está dado a partir de si mesmo. A epoké pode trazer uma contribuição para a reflexão sobre sujeito nas pesquisas em Psicologia da Saúde. A necessidade de colocar a realidade entre parênteses aponta para o fato de que o real não se dá de maneira clara e evidente, como afirmara o cartesianismo. A atitude fenomenológica supõe outro conceito de verdade, entendido como resistência, aletheia. Diante disso, o sujeito que faz pesquisa em Psicologia da Saúde, ao entrar em contato com determinada realidade, seja ela, humana, animal, bibliográfica deve colocar-se na posição daquele que permite que o fenômeno do participante ou realidade manifeste-se a partir de si mesmo, no conjunto do vivido no qual pesquisador e participante, ou pesquisador e realidade pesquisada comparecem como alteridades que oferecem resistência e por isso, são reais. É o conjunto do vivido, como espaço no qual os seres comparecem como alteridades, sob a forma de resistência, e não o sujeito, que possibilita a consciência se estruturar fenomenologicamente como consciência de algo que, por assim ser, pode acessar as realidades dos fenômenos da maneira como eles se apresentam.

Não obstante, a relação entre sujeito intencional e objeto fenomenológico se dá porque, para Husserl (1950), existe uma estrutura transcendental que dá suporte e funciona como horizonte de possibilidade para o próprio sujeito que conhece. Essa estrutura é necessária por dois motivos. O primeiro é o fato de que, sem ela, o ego ficaria fechado em si mesmo, pois não haveria nenhum horizonte de suporte que possibilitasse o movimento intencional da consciência para com o fenômeno; o segundo é que, com essa estru- tura, Husserl dá ao cogito a abertura necessária para que ele não seja mais hermeticamente fechado sobre a estrutura do ego, mas esteja aberto para o próprio fato das suas vivências e das suas experiências, sejam elas reais, sejam da consciência. Sobre isso, comenta Husserl: "A certeza apodítica da experiência transcendental apreende o meu Eu sou transcendental como implicante a indeterminação de um horizonte aberto" (2001, p. 81).

A estrutura transcendental do cogito possibilita ao sujeito dois movimentos importantes para a apreensão de si mesmo e do mundo. O primeiro com relação a si é o tempo sob a forma de percepção e consciência do tempo, porque este aparece como horizonte das possibilidades do cogito tanto para o passado, quanto para o futuro. O segundo é o corpo, como horizonte de possibilidade de apreensão e relação intencional com a realidade.

Pensando isso dentro do horizonte das pesquisas em Psicologia da Saúde, um dado importante apresenta-se, pois, se a temporalidade a corporeidade são os caminhos pelos quais o sujeito pode apreender e interagir consigo mesmo e com o mundo, o fato de fazer pesquisa deixa de ser apenas um atributo teórico e passa a ser um exercício existencial. Ao fazer pesquisa o pesquisador desenvolve-se e se compromete existencialmente. Ao considerar isso dentro da abordagem Biopsicossocial é possível notar mais uma aproximação, pois a consideração da vida do pesquisador, dos participantes, como um fenômeno existencial e de comprometimento, acaba se tornando um elemento importante no processo de construção da vida do pesquisador e dos participantes. Fazer pesquisa torna-se muito mais do que um exercício intelectual, este passa a ser um exercício de estabelecimento de relações de alteridade cujo produto final, é o desenvolvimento de uma experiência vital. Os relatórios de pesquisa, diante disso, se tornam apenas expressões metodologicamente organizadas de uma experiência vital, vivida como corporeidade intencionalmente presente no mundo dentro da modalidade de ser pesquisador-participante da pesquisa.

Consideradas as reflexões acima, é possível perceber que Husserl acaba organizando a consciência como uma estrutura transcendental de projeção em direção ao mundo. Porém como isso se dá? Para responder a essa pergunta, é preciso refletir sobre aquilo que Husserl vai chamar de constituição ativa da consciência transcendental, a qual ele entende como 
os processos que o sujeito desenvolve para interagir consigo mesmo e com o mundo de maneira intencional e posicionada. Contudo como se dá essa relação entre consciência do mundo dentro de uma estrutura de constituição ativa? A resposta pode ser encontrada naquilo que Husserl vai chamar de estrutura sinestésica, ou estrutura da percepção, isto é, a consciência que percebe a si mesma e ao mundo acaba adquirindo conteúdos mentais, hilé (Hilḱ), que modificam a própria consciência. Esses conteúdos são captados por meio dos sentidos dentro do movimento da redução fenomenológica.

Ao se observar como estas categorias dialogam com o universo da pesquisa, e em particular a pesquisa em Psicologia da Saúde, é possível perceber que, se os conteúdos mentais, as hilés, modificam a própria consciência elas acabam por influenciar, senão modificar, a experiência subjetiva do mundo. O pesquisador no ato de fazer a pesquisa é modificado por ela, a sua percepção de mundo é afetada pelo mundo com o qual ele interage. Portanto, um pesquisador que se dedica a pesquisar Saúde ou qualidade de vida estará mais sensível a certas realidades materiais e conceituais do que outros que não se dedicam a isso. Daí o porquê de temas como discurso de gênero, subjetividade, pluralidade, diversidade, qualidade de vida, saúde serem tão presentes na vida dos pesquisadores de Psicologia da Saúde. Contudo, qual é o lugar privilegiado no qual o pesquisador faz a experiência de ser copresente e influenciado pela pesquisa?

A estrutura da percepção, da copresença e da experiência se dá por um determinante fundamental, o corpo, que na obra Ideias II: Pesquisas fenomenológicas para uma constituição será chamado por Husserl (1982) de órgão da percepção. A partir daí, surge dentro do cenário da reflexão de Husserl a temática do corpo próprio em contraposição ao corpo objetivo que é oposto a consciência (Buissière, 2005). O corpo próprio caracteriza-se pelo ser vivo, o corpo vivente que faz experiência de ser si mesmo no mundo com os outros, já o corpo objetivo é o körper, o organismo, a somatória dos órgãos. A reflexão sobre o corpo dessa consciência que vai de maneira intencional em direção ao fenômeno revela algo singular dentro de um campo epistemológico que originalmente tinha por objetivo conhecer os processos de como o cogito conhece e interage com o mundo.

$\mathrm{Na}$ reflexão de Husserl, o corpo apresenta-se como a solução para a questão do conhecimento.
Este se torna o lugar onde o sujeito lógico e o sujeito ontológico podem dialogar, haja vista que até aqui a grande pergunta era: como uma consciência que se arroga processos universais e abstratos, a partir de uma realidade imanente, pode se constituir como sujeito? Qual é o elo que há entre a transcendentalidade do sujeito lógico com as vivências que produzem as estruturas hylético-perceptivas? A estrutura somática não é pensada apenas como um suporte, ou como algo secundário dentro dessa reflexão, mas como uma constatação fundamental, a saber: que na estrutura da percepção há uma presença, personalizada, em carne e osso do objeto. Sobre isso, comenta Husserl,

O corpo próprio é causa tanto dos órgãos dos sentidos e da totalidade dos órgãos do sentido livremente movidos e assim, a partir do seu fundamento original, a todo o real das coisas do mundo circundante ao ego e a sua relação com o corpo próprio (1982, p. 92).

Com isso é possível perceber que o corpo vai aos poucos ocupando um lugar fundante dentro do pensamento de Husserl. Ele é o horizonte de eventos da percepção, pois este não é um movimento abstrato do cogito, do sujeito lógico, mas um ato de experiência fundada na concretude da vivência. Ele é a forma de constituição do sujeito no mundo e é por isso que o mundo pode-lhe ser imanente, e os objetos podem-se doar por meio de uma interioridade-exterioridade. Trazendo isso para a discussão sobre o sujeito da pesquisa em Psicologia da Saúde é possível perceber que ao tratar temas como Saúde e doença, o pesquisador muito mais do que discutir atributos teóricos está refletindo sobre a sua própria experiência de Saúde, e experiência de mundo.

O corpo próprio, como único caminho que o cogito tem para a percepção e para a interação com o mundo, faz com que Husserl comece a refletir sobre uma camada inferior, sobre uma nova constituição anterior à consciência e dela constituinte, realidade essa que não está ligada aos predicativos da redução fenomenológica, mas aos antepredicativos, que não têm como matéria da redução sinestésica as hilé, (Hyle), mas a primeira/anterior Hilé, (Ur-Hyle). A pergunta de Husserl pelas condições genéticas do si abre um novo caminho para a investigação da natureza própria do fenômeno a que Husserl dá o nome de Síntese passiva, em oposição à síntese intencional, ativa do ego puro. Sobre isso comenta Husserl, "A construção pela atividade pres- 
supõe sempre e necessariamente, como camada inferior, uma passividade que recebe o objeto e o encontra como fato; analisando nós chegamos à constituição por meio da síntese passiva" (1953, p. 40).

Com a afirmação da síntese passiva, ou constituição genética do sujeito, chega-se a uma camada, para usar a expressão de Husserl, que faz a ligação entre a consciência e o horizonte do sentido, pensado como estrutura constitutiva que escapa à consciência e à redução da síntese ativa. Aqui se opera no horizonte no qual a subjetividade se constitui a si mesma a partir do modo da receptividade. Sobre isso comenta Montavont:

Enraizando a receptividade numa passividade ainda mais original, o pré-doação afetiva, e afirmando a atividade dentro de uma passividade englobante, ele (Husserl) muda as fronteiras tradicionais entre a sensibilidade e a espontaneidade, entre sensível e inteligível (1999, p. 10).

Exposto esse cenário, agora é possível refletir sobre as estruturas que dão suporte a experiência humano do mundo. A partir daqui um horizonte importante se desvela. Trata-se do tema do sujeito carnal, ou da estrutura somático-estética da subjetividade.

Qual a importância de partir do corpo para se pensar uma síntese passiva (Husserl, 1998) e uma constituição genética do sujeito? Por que a temática do corpo acaba aparecendo numa discussão que busca entender a relação entre o sujeito lógico e o sujeito ontológico e os seus impactos na pesquisa em Psicologia da Saúde?

O fenômeno da percepção do mundo e de si mesmo, por meio da temporalidade e da corporeidade, abriu, dentro da discussão fenomenológica, a possibilidade de refletir sobre a passividade sob a forma de estar posicionado no mundo. O corpo, como órgão da percepção e do estar posicionado, passa a ser não mais a forma de acesso da consciência aos fenômenos imanentes, mas a forma de acesso do cogito ao ser; portanto, pensá-lo como estrutura somática, como carne e osso, é fundamental para se entender a relação que há entre ser e pensamento. A constatação do fenômeno da passividade, como camada inferior e constitutiva do sujeito lógico, revelou que este não é apenas uma consciência transcendental abstrata, mas que fundamentalmente se define como sujeito encarnado. "É unicamente pela relação empírica com o corpo que a consciência se torna uma consciência humana e animal de maneira real" (Husserl, 1982, p. 86-87).
É preciso, para se trilhar em profundidade dentro desse caminho para o conhecimento, refletir não mais sobre a influência ativa da consciência, mas sobre a unidade do conteúdo objetal-hilético que aparece no movimento reflexivo da consciência como síntese temporal a partir de si mesma. Para se operar dentro dos limites dessa síntese constitutiva, faz-se necessário entender que existe uma unidade da realidade que se apresenta, por meio da percepção no corpo e do corpo, como obra do tempo e que será compreendida como unidade se considerada dentro do tempo. É somente na síntese temporal da inatividade originária da consciência encarnada no corpo próprio que se consegue entender as estruturas originárias da subjetividade (Heidegger, 2012).

Esta estrutura encarnada do sujeito se apresenta com duas características: a primeira é a sua materialidade, a sua dimensão de concretude que faz dela um corpo sensível e um corpo encarnado e material e a segunda característica é a reflexibilidade, pois, quando a pessoa sente ou percebe um objeto, também percebe a si mesma (Husserl, 1998). Todas as sensações cinestésicas produzem como efeito a percepção do corpo como próprio, Leib, e não como algo físico exterior. Por exemplo, quando se toca algo com as mãos, uma pessoa percebe o objeto tocado e também percebe a si mesma tocando o objeto. Essa dimensão da reflexibilidade do corpo revela que conhecer um objeto supõe uma experiência somática e psíquica e que o corpo próprio, é ao mesmo tempo uma estrutura material de vivência que possibilita a consciência de interagir com o exterior e é também a estrutura da própria subjetividade, comenta Husserl "Um sujeito que não fosse vivo não poderia ter absolutamente nenhum corpo próprio aparecendo" (1982, p. 66). Isso leva à compreensão de que corpo próprio é o corpo vivo.

As reflexões de Husserl sobre a constituição ativa da subjetividade permitem perguntar sobre como se dá a relação entre a vida do pesquisador no processo de construção da pesquisa? As relações entre Adição ao trabalho e Saúde, Produtivismo acadêmico e o Bem-estar dos pesquisadores são temas, que, à luz das considerações sobre o corpo próprio, ganham relevância não apenas no que toca a qualidade teórica das pesquisas, mas sim, no impacto existencial que o ato de ser sujeito fazendo pesquisa produz. A redescoberta do corpo próprio abre espaço para a pergunta sobre o lugar no qual esse indivíduo se encontra, isto, na coletividade, como alteridade de alteridade, construindo-se como pesquisador em Psicologia da Saúde. 


\section{Considerações finais}

A pergunta pelas características predicativas e denominativas da constituição lógica do sujeito nos permite pensar a denúncia que Husserl (1994) faz com relação aos homens que produzem ciência de fatos. Ao se pensar a relação entre o sujeito da pesquisa e a vida daquele que faz a pesquisa em Psicologia da Saúde, é possível perceber que a passagem entre o conceito lógico de sujeito à vida do pesquisador não é linear nem homogênea, pois o sujeito lógico da pesquisa, por se tratar de uma estrutura lógico-formal sem conteúdo prévio, ou seja, por ser apenas uma categoria lógica. Por sua vez, o sujeito ontológico, o existente que exerce os seus modos de ser no movimento de dar razões às suas possibilidades existenciais apresenta-se como finito e mortal. O projeto kantiano de criação do ego transcendental acabou por tomar como a fortiori a correspondência entre o sujeito lógico e sujeito ontológico. Uma ciência ou modelo epistemológico que não toma em consideração essa realidade acabará incorrendo no erro de propor modelos que, em vez de afirmar e promover a vida, ou então buscar minimizar e defender as fragilidades e vulnerabilidades das pessoas, acabará propondo modelos lineares que se atêm apenas à estrutura formal, desconsiderando que o sujeito que pesquisa e que participa da pesquisa, muito mais do que um sujeito lógico, é cada pessoa na sua singularidade de ser si mesmo no conjunto das suas possibilidades. Sem essa consideração, as iniciativas de promoção e manutenção da vida correm grande risco de se tornarem estratégicas de transformação do real em um atributo de uma consciência que não sabe de ser, não sabe da vida, não sabe da morte.

O intento da Fenomenologia husserliana é o de buscar na singularidade de cada vida, no corpo próprio, na experiência de mundo como horizonte de pensamento e construção da ciência uma possibilidade para se chegar a verdade do ser. Husserl percebeu que a atribuição ou sobreposição direta entre sujeito lógico e sujeito ontológico acabou produzindo como um de seus resultados o idealismo. Os corpos vivos dos sujeitos ontológicos sentiram em suas próprias carnes os resultados do desprendimento de um sujeito lógico.

Por isso faz-se necessário redescobrir o sujeito ontológico como pessoa vivente, como ser corpóreo que, por possuir essa constituição, é capaz de aproximar-se da verdade. Por fim, com Husserl e todos os movimentos do começo do século XX, observa-se a redescoberta do corpo, num primeiro momento, ainda muito influenciado pelo modelo mecanicista, porém que aos poucos vai adquirindo uma dimensão de corpo vivo e corpo de um ser vivo, no caso, ser humano.

O caminho da modernidade mostrou que o sujeito contemporâneo é herdeiro de uma visão de mundo que produziu um modus vivendi que ainda exerce muita influência sobre a forma de ver e agir do indivíduo no mundo, principalmente naquilo que toca às pesquisas em Psicologia da Saúde e políticas de qualidade de vida. Revisitar esses autores da modernidade ajudou a perceber que, pelo fato da eleição do sujeito como critério de validação da realidade e com a objetivação da própria pessoa, um novo tipo de relação humana nasceu e, como efeito disso, uma nova imagem de mundo. A eleição do modelo subjetivo influenciado pela correspondência direta entra estrutura lógica e estrutura ontológica acabou dando visibilidade a uma realidade que afeta profundamente as pesquisas na contemporaneidade, pois o sujeito da ciência, muitas vezes, não considera o pesquisador concreto, nas suas particularidades e singularidades. O sujeito lógico da ciência parece pressupor a existência de um corpo próprio, encarnado, real, posicionado que interage com o mundo e busca, na unidade da pessoa, construir a sua história como projeto aberto que necessita e produz cuidado. Quando as práticas protocolares de pesquisa em Psicologia da Saúde forem suficientemente porosas para permitirem o atravessar do sujeito encarnado, a humanidade estará adentrando o limiar de uma ciência que se estrutura fundamentalmente como afirmação da vida.

A Fenomenologia, de maneira particular a das sinteses passivas, pode ajudar no processo de reflexão sobre a qualidade de vida dos pesquisadores e dos participantes da pesquisa em Psicologia da Saúde, pois, se a pesquisa é feita por seres humanos, posicionados como e em seu corpo próprio no mundo da vida, é preciso pensar quais são as estratégias para fazer com que a experiência de mundo e de si mesmo que essas pessoas fazem, ao construírem-se dentro do modo de ser da pesquisa. O sujeito abstrato lógico não sofre resistência de um real que está para ele apenas como conteúdo denominativo dentro de uma relação de sujeito e predicado. Por sua vez, o sujeito ontológico, que vive no mundo e é capaz de se perguntar pelo sentido dele, sofre a resistência dessa realidade e estabelece uma relação de morada com ele. 
Frente a isso, temas comuns em Psicologia da Saúde como a discussão sobre o modelo produtivista em relação a qualidade de vida dos pesquisadores; a discussão da Saúde como algo para além do modelo Biomédico; a relação entre qualidade da pesquisa e comprometimento ético parecem ganhar novas ferramentas teóricas para a reflexão. Os limites dessa pesquisa assentam-se na própria delimitação do tema escolhido para se pesquisa.

Um dos temas de trabalho que a discussão acima permite é: qual a relação entre a constituição do corpo sob a forma de Körper, organismo e o modelo Biomédico? Como as sínteses passivas podem ajudar no pro- cesso de construção de ambiente vitais no qual a dimensão da Saúde como fenômeno Biopsicossocial possa se desenvolver? A opção por se perguntar pelas pré-condições ou estruturas genéticas da subjetividade trouxeram como oportunidades o fato de pode ser pensar os elementos estruturantes de tal tema, contudo, isso exigiu do leitor um esforço teórico para se pensar em níveis de realidade conceituais que são estruturantes, mas, abstratos. Um campo a ser explorado, e que constitui um limite dessa reflexão, foi o da análise de como modelos teóricos e paradigmas lógicos, como o do sujeito cartesiano acabam produzindo impactos reais na vida das pessoas.

\section{Referências}

Buissière, E. (2005). Cours sur les corps. Paris: Philosophie.

Copernicus, N. (1984). As revoluções dos orbes celestes. Lisboa: Fundação Calouste Gulbenkian. (Original publicado em 1543).

Demarco, M. (2003). A face humana da medicina: do modelo biomédico ao modelo biopsicossocial. São Paulo, SP: Editora Casa do Psicólogo.

Descartes, R. (2001). Discurso sobre o método. São Paulo, SP: Martins Fontes. (Original publicado em 1637).

Descartes, R. (2004). Meditações sobre a filosofia primeira. Campinas, SP: Editora Unicamp. (Original publicado em 1641).

Dimenstein, M. D. B. (1998). O Psicólogo no contexto do Sistema Único de Saúde (SUS): Perfil profissional e perspectivas de atuação nas unidades básicas de saúde. (UBS) (Tese de Doutorado). Universidade Federal do Rio de Janeiro, Rio de Janeiro, RJ, Brasil.

Figueireido, L. C. (2016). Matrizes do pensamento psicológico. 20a ed. Petrópolis, RJ: Vozes.

Figueiredo, L. C. M; Santi, P. L. R. (2016) Psicologia: Uma (nova) introdução. 3a ed. São Paulo, SP: EDUC

Foucault, M. (2000). As palavras e as coisas: Uma arqueologia das ciências humanas. São Paulo, SP: Martins Fontes.

Furlanetto, J. (1965), Lexicon Totius Latinitatis. Bologna: Anastatische Herduk.

Galileo, G. (1638). Dialogo. Florença: Gio. Battista Landini.

Gonzalez-Rey, F. L. (2003). Subjetividade e sujeito: Uma aproximação histórico-cultural. São Paulo: Thomson Learning.

Heidegger, M. (2012). Ser e tempo. Petrópolis, RJ: Vozes.

Husserl, E. (2012). A crise das ciências europeias e a fenomenologia transcendental: Uma introdução à filosofia fenomenólica. Rio de Janeiro, RJ: Forense Universitária.

Husserl, E. (1998). De la synthèse passive. Paris: Millon.

Husserl, E. (1950). Idées directrices pour une phénoménologie. Paris: Gallimard.

Husserl, E. (2001). Meditações cartesianas. São Paulo, SP: Madras.

Husserl, E. (1953). Meditations Cartesienes. Paris: Librairie Philosophique.

Husserl, E. (1982). Recherches phénoménologique pour la constitution. Paris: PUF.

Kant, I. (2006). Antropologia de um ponto de vista pragmático. São Paulo, SP: Iluminuras. (Original publicado em 1798).

Kant, I. (2001). Crítica da razão pura. 5a ed. Lisboa: Fundação Calouste Gul-benkian. (Original publicado em 1781).

Kant, I. (1974). Fundamentação da metafisica dos costumes. São Paulo, SP: Abril Cultural. (Original publicado em 1785).

Kant, I. (2003). Metafísica dos costumes contendo a doutrina do direito e a doutrina da virtude. São Paulo, SP: Edipro. (Original publicado em 1781). 
Le Breton, D. (2012). Antropologia do corpo e modernidade. Petrópolis, RJ: Vozes.

Matarazzo, J. D. (1982). Behavioral health's challenge to academic scientific and professional psychology. American Psychologist, 37(1), 1-14.

Montavont, A. (1999). De la passive é dans la phénomenologie de Husserl. Paris: PUF.

Nietzsche, F. (2009). Para além do bem e do mal. São Paulo, SP: Companhia das Letras. (Original publicado em 1886).

Slva, R. C. (1992). A formação em psicologia para o trabalho na saúde pública. In: F. C. B. Campos, Psicologia e saúde: Repensando praticas (pp. 25-40). São Paulo, SP: Hucitec.

Smith, A. (1976). An inquiry inti the nature and causes of the wealth of Nation. London: Willian Strahan.

Spink, M. J. (2003). Os Psicólogos na saúde: Reflexões sobre os contextos da pratica profissional. In: M. J. Spink, Psicologia social e saúde: Práticas, saberes e sentidos (pp.77-159). Petrópolis, RJ: Vozes.

Taylor, S. E. (2002). Health psychology. 5th ed. New York, NY: McGraw-Hill.

Vesalius, A. (1543). De humani Corporis Fabrica. Basel: Caesarea.

\section{Gillianno José Mazzetto de Castro}

Doutorando em Psicologia pela Universidade Católica Dom Bosco. Campo Grande - MS. Brasil.

E-mail: gillianno@gmail.com

\section{Marcio Luis Costa}

Doutor em Filosofia pela Facultad de Filosofía y Letras da Universidad Nacional Autónoma de México. México - DF. México.

E-mail: marcius1962@gmail.com

Endereço para envio de correspondência:

Universidade Católica Dom Bosco, Pró-reitoria de Desenvolvimento Institucional, Av. Tamandaré, 6000 - Jardim

Seminário. CEP: 79010-200.

Campo Grande - MS. Brasil.

Recebido 26/07/2017

Aprovado 12/01/2018

Received $07 / 26 / 2017$

Approved 01/12/2018

Recibido 26/07/2017

Aceptado 12/01/2018

Como citar:Castro, G. J. M., \& Costa, M. L. (2018). A invenção do sujeito. Psicologia: Ciência e Profissão, 38(2), 391-402. https://doi.org/10.1590/1982-3703003012017

How to cite: Castro, G. J. M., \& Costa, M. L. (2018). The invention of the subject. Psicologia: Ciência e Profissão, 38(2), 391-402. https://doi.org/10.1590/1982-3703003012017

Cómo citar: Castro, G. J. M., \& Costa, M. L. (2018). La invención del sujeto. Psicologia:Ciência e Profissão, 38(2), 391-402. https://doi.org/10.1590/1982-3703003012017 